\title{
Custos para servir: um estudo em uma indústria de etiquetas personalizadas
}

\section{Costs to serve: a study in a customized label industry}

\author{
Maria Júlia Bitencourt Colombo Bacharel em Ciências Contábeis pela Universidade do Extremo Sul Catarinense (UNESC), Brasil. \\ jujucolombo@hotmail.com \\ Januário José Monteiro Doutorando no Programa de Pós-Graduação em Contabilidade (PPGC) da Universidade Federal \\ de Santa Catarina (UFSC), Brasil. januariomonteiromonteiro@gmail.com \\ Andreia Cittadin Doutoranda no Programa de Pós-Graduação em Contabilidade (PPGC) da Universidade Federal \\ de Santa Catarina (UFSC), Brasil. aci@unesc.net
}

\section{RESUMO}

A pesquisa teve por objetivo evidenciar o resultado dos principais clientes de uma indústria de etiquetas personalizadas com a aplicação dos custos para servir. A partir de uma abordagem qualitativa e descritiva foi realizada um estudo de caso. Os dados foram obtidos mediante entrevista e análise documental. Os resultados apontaram que o processo produtivo da empresa contempla quatro grupos de atividades, que foram categorizadas em Administrativo, Comercial, Desenvolvimento e Produção. As atividades Comercial e Produção consumiram mais recursos indiretos no período, em torno de $53 \%$ e $22 \%$, respectivamente. Os custos mais representativos foram salários e encargos, Pró-labore e comissões, que perfizeram $70 \%$ dos custos indiretos totais. A lucratividade global da empresa representou 7,56\%, porém os clientes B e $C$ apresentaram prejuízo de $10 \%$ no período analisado, principalmente devido aos elevados custos indiretos nas atividades Comercial e Desenvolvimento. Conclui-se que a aplicação da técnica custos para servir revela diversas informações para a gestão dos negócios, mas requer uma série de controles que exigem mudança de cultura e capacitação dos indivíduos envolvidos com o gerenciamento de custos. Estas evidências enfatizam a importância do gerenciamento de custos, em organizações que adotam o sistema de custeio por ordem.

Palavras-chave: Gestão Estratégica de Custos. Custo para servir. Indústria de etiquetas

\section{ABSTRACT}

The research aimed to highlight the results of the main customers of a customized label industry with the application of Costs to Serve. Based on a qualitative and descriptive approach, a case study was carried out. The data were obtained through interviews and documentary analysis. The results showed that the company's production process includes four groups of activities, which were categorized into Administrative, Commercial, Development, and Production. Commercial and Production activities consumed more indirect resources in the period, around $53 \%$ and $22 \%$, respectively. The most representative costs were salaries and charges, Pro-labore and commissions, which accounted for $70 \%$ of the total indirect costs. The company's global profitability represented $7.56 \%$, but customers B and C showed a loss of $10 \%$ in the period analyzed, mainly due to the high indirect costs in the Commercial and Development activities. It is concluded that the application of the Costs to Serve technique reveals several information for business management but demands a series of controls that require a change in culture and training of individuals involved with cost management. This evidence emphasizes the importance of cost management in organizations that adopt order costing system.

Keywords: Strategic Cost Management. Cost-to-serve. Label industry 


\section{INTRODUÇÃO}

No atual contexto econômico as organizações enfrentam o desafio constante de se destacarem perante a concorrência, quer seja pela diferenciação na qualidade dos produtos e excelência nos serviços ou pela estratégia de baixo custo. Além disso, os produtos apresentam diminuição do ciclo de vida, fator que compromete a garantia de continuidade das empresas. Diante dessas demandas, existe a necessidade do uso de instrumentos gerenciais que assegurarem a melhoria do desempenho organizacional (Blocher, Stout \& Cokins, 2010).

No intuito de se tronarem mais competitivas as empresas buscam instrumentos de gestão de custos mais eficazes, uma vez que os métodos tradicionais de análise de custos fornecem maior atenção ao custo dos produtos e pouca atenção aos custos para servir os clientes (Braithwaite \& Samakh, 1998), por isso são insuficientes para identificar a lucratividade por cliente. Nessa linha, Braithwaite e Samakh (1998) registraram a marca cost-to-serve no intuito auxiliar na apuração dos custos incorridos para atender os clientes. Essa abordagem visa quantificar os custos decorrentes do atendimento das demandas de um cliente (Kone \& Karwan, 2011) e sua identificação é desafiadora e indispensável para a empresa, pois permite gerenciar as estratégias de preço e lucratividade (Freeman, Haaz, Lizzola \& Seiersen, 2000).

Para verificar a rentabilidade que determinado cliente gera para a organização é preciso evidenciar por completo os custos incorridos no seu atendimento (Fernandes, Faria, Crispim \& Fernandes, 2014). Nesse sentido, Norek e Pohlen (2001) explicam que dois clientes podem ter o mesmo volume de venda, preço e quantidade, mas para atendê-los a empresa requer um esforço diferente, fator que evidencia que eles não geram a mesma rentabilidade.

Assim, o conhecimento sobre as receitas e custos no nível de cliente é pertinente para as organizações (Atkinson, Kaplan, Matsumura \& Young, 2015). Principalmente para aquelas que não possuem instrumentos de gestão adequados para ao menos identificar seus custos em relação aos produtos ou serviços. Consciente da importância de estudos que tratam da abordagem sobre custos para servir (Braithwaite \& Samakh, 1998), do interesse da literatura em compreender as problemáticas inerentes aos custos para servir cliente (Kone \& Karwan, 2011) e da necessidade das organizações em identificar os clientes mais lucrativos em vista da manutenção da carteira de clientes (Souza, Marçal \& Gasparetto, 2019), esta pesquisa se alinha aos estudos anteriores e tem por objetivo evidenciar o resultado dos principais clientes de uma indústria de etiquetas personalizadas com a aplicação dos custos para servir.

A importância do estudo se dá no campo teórico por se alinhar aos estudos que sugeriram mais pesquisas sobre a temática (Braithwaite \& Samakh, 1998; Kone \& Karwan, 2011) e analisar a lucratividade dos principais clientes de modo a melhorar o processo de tomada de decisão no nível de cliente (Souza et al., 2019). Com isso, se busca contribuir para a literatura que trata da temática custos para servir. A relevância do estudo consiste na compreensão de como os custos são gerenciados (Cunha, Castanha, Monteiro, Vieira, \& Cittadin, 2018), principalmente em uma organização que adota o sistema de custeio por ordem, uma vez que é imprescindível para a continuidade das atividades na organização (Souza, Avelar \& Boina, 2008) e porque os custos são analisados de forma distinta entre os clientes (Hansen \& Mowen, 2006), o que melhora a acurácia das informações.

A proposta visa evidenciar os custos para servir os clientes em uma organização de pequeno porte do setor têxtil, indispensável para a economia local, em específico no sul do Estado de Santa Catarina (SC). De acordo com SINDIVEST (2010), SC é considerada o segundo polo têxtil de vestuário no Brasil e o ramo de confecções e têxtil tem participação de $18,71 \%$ na indústria catarinense. Assim, estudos que se propõem compreender o processo gestão de empresas de pequeno porte geram contribuições teóricas para o campo de pesquisas sobre empresas familiares, práticas e sociais (Becker, Monteiro, Castanha, \& Cittadin, 2020), uma vez que, melhorar o conhecimento sobre a lucratividade por cliente pode permitir a construção de estratégias em vista da atração de novos clientes (Souza et al., 2019) e, consequentemente, alcance de melhor resultado e manutenção das atividades. Pode ainda contribuir para as decisões estratégicas que envolvam relacionamento com terceiros e decisões em relação aos investimentos (Souza, Noveli, Minello, Endrici, \& 
Avelar, 2006), bem como o processo de formação do preço de venda que pode ser distinto entre os clientes (Souza et al., 2008).

\section{REVISÃO DA LITERATURA}

\subsection{Custos para servir}

Em vista da busca pela competitividade as empresas precisam considerar os preços praticados no mercado e uso de tecnologia que possibilita a geração de informações tempestivas e eficazes para os administradores e seus colaboradores (Martins, 2003; Mattos, Freitag \& Starke Junior, 2010). Por isso buscam métodos eficazes (Braithwaite \& Samakh, 1998) no intuito de diminuírem seus custos e aumentarem sua lucratividade (Gensler, Leeflang \& Skiera, 2012) e, com isso, desenvolverem vantagem competitiva no mercado.

Cada método de custeio apresenta contribuições para algum tipo de informação, função e finalidade. Dessa forma, as empresas devem analisar qual atende suas finalidades e se mostra mais eficaz para colocar em prática. Após analisar os benefícios e vantagens se deve implantar uma estratégia para o sucesso das atividades (Mauad \& Pamplona, 2001). Contudo, as práticas tradicionais da contabilidade de custos como, por exemplo, o custeio variável, o custeio por absorção e custo padrão, não são suficientes para identificar a lucratividade que cada cliente traz efetivamente para a empresa, em um ambiente econômico altamente competitivo (Mauad \& Pamplona, 2001).

De acordo com Mattos et al. (2010), ao longo do tempo novos métodos têm sido utilizados para suprir as necessidades dos usuários internos da contabilidade gerencial. Um instrumento que surgiu para suprir tal necessidade é a utilização da técnica custos para servir, que busca reconhecer a lucratividade de cada cliente em particular (Braithwaite \& Samakh, 1998; Faria, Borinelli \& Mantovani, 2010; Souza et al., 2019).

Nesse contexto, o custo relacionado aos clientes despertou atenção dos acadêmicos e profissionais, pois sua identificação pode contribuir para a empresa se destacar no mercado e aumentar sua lucratividade (Braithwaite \& Samakh, 1998; Guerreiro, Bio \& Merschmann, 2008). Guerreiro et al. (2008) enfatizam que nas empresas que possuem diversos produtos é mais difícil encontrar o custo específico de um determinado produto. Assim, uma ferramenta como a margem de contribuição não é o suficiente para visualizar a rentabilidade dos clientes. Logo, torna-se relevante o cálculo dos custos para servir para a identificação do lucro individual dos clientes. A partir desse conhecimento a organização consegue focar seus esforços nesses clientes para aumentar o resultado global da empresa no final do período. Nesse sentido, Souza et al. (2019) elucidam que a análise dos custos para servir permite a organização tomar decisão em nível do cliente já que informações gerenciais obtidas pela produção não são suficientes para tal.

A identificação dos custos para servir não compreende um padrão estabelecido para todas empresas, uma vez que cada organização possui características que devem ser consideradas durante o processo (Braithwaite \& Samakh, 1998). Para Robles, Robles e Faria (2005) e Faria et al. (2010), as organizações buscam identificar os custos para servir, a fim de encontrarem a real rentabilidade para a empresa, pois cada cliente exige um tempo e atendimento diferenciado. Para se determinar o lucro é preciso reconhecer custos como: os de pré-venda, os de distribuição e os de pós-venda (Faria \& Costa, 2005). Para os autores, os custos de prévenda são aqueles que exigem uma ação entre fornecedor e cliente; os custos de distribuição são aqueles que dependem da localização, da distância, do meio de transporte utilizado, do combustível e do acesso ao local; custo da pós-venda é aquele que disponibiliza ao cliente a assistência. Torna-se pertinente ter conhecimento desses gastos para a melhor determinação da rentabilidade de cada cliente.

Conforme Faria et al. (2010) é necessária uma mudança de paradigmas em vista da implementação da abordagem custos para servir, já que nem sempre é possível identificar facilmente todos os custos relacionados ao produto. Na concepção de Howcroft (2005) para utilizar a abordagem custos para servir e alcançar seus objetivos é necessária uma iniciativa interna na empresa, no intuito de saber qual cliente gera mais lucratividade e qual cria maior valor para a organização. 
Por meio do estudo realizado por Kaplan (1989) e apresentado por Kaplan e Cooper (1998), foi possível identificar que $20 \%$ dos clientes mais lucrativos geravam $225 \%$ do total de lucros, $70 \%$ dos clientes estavam no ponto de equilíbrio e $10 \%$ geravam prejuízo correspondente a $125 \%$ do total de lucros.

Destaca-se que, devido a necessidade de identificar a lucratividade individual de cada cliente a partir da identificação dos custos para servir é possível pelo uso do ABC (Activity Based Costing) (Guerreiro et al., 2008). Portanto, se sabe que os custos para servir é uma derivação do Custeio Baseado em Atividades (ABC), devido ao fato que é preciso identificar os custos indiretos e diretos dos produtos e serviços. Nessa linha, Braithwaite e Samakh (1998) esclarecem que a abordagem custos para servir se baseia no $A B C$ e por isso não pode ser considerado um método propriamente dito.

\subsection{Método de custeio ABC (Activity Based Costing)}

Devido a carência de um método de custeio que reconhecesse adequadamente os custos indiretos aos produtos e serviços, surgiu o ABC. Essa metodologia de identificar os custos indiretos incorridos no processo de produção tornou-se essencial, tendo em vista que nos outros métodos esses custos, muitas vezes, não são reconhecidos de modo eficaz. $O A B C$ permite alocar os custos indiretos de três modos diferentes: a) por produtos; b) por canal; e c) por clientes. Baseando-se nos resultados obtidos em cada atividade, os administradores conseguem verificar em qual atividade o consumo está sendo maior (Faria \& Costa, 2005).

Conforme Cokins (2006), o ABC utiliza os produtos, as linhas de serviço, os canais e os clientes para encontrar o custo final. Para conseguir informações precisas e eficazes é preciso identificar o custo de todas as atividades indiretas relacionadas ao produto ou serviço. $O$ diferencial desse método é que ele evidencia os custos indiretos do início ao fim, ou seja, desde o processo de fabricação do produto até o suporte final ao cliente. Cooper e Kaplan (1991) elucidam que esse método possibilitam um diagnóstico da situação com vistas a maximização da lucratividade.

$O A B C$ se destaca nas organizações, por ser o método que possibilita fazer o cálculo dos custos indiretos com mais exatidão, além de agregar as áreas de vendas, transportes, distribuição e logística. Sendo assim, a diferença em relação aos outros métodos de custeio é o tratamento em relação aos custos indiretos (Nakagawa, 2001).

Martins (2010) salienta que o $A B C$ tem como objetivo os processos e, a partir destes, a empresa evidencia quais atividades incluir no custeio. Portanto, é possível identificar o quanto gasta em cada uma dessas atividades. Uma das vantagens de implantar $O A B C$ é a possibilidade de tornar a organização mais competitiva, devido à informação útil que esse método de custeio proporciona. Para Ferreira (2007), o ABC tem como finalidade diminuir as distorções causadas pelos outros métodos de custeio, fornecer informações sobre os custos dos produtos, exigindo maior registro de dados. Contudo, esse método de custeio apresenta algumas fragilidades como dificuldades na coleta e registro dos dados.

Os custos indiretos são aqueles que ocorrem em diversos processos da entidade. Assim no custeio $A B C$ são distribuídos inicialmente para as atividades e, posteriormente, aos produtos e serviços. Portanto, torna-se fundamental apurar os custos indiretos no intuito de encontrar o valor mais próximo da realidade (Santos \& Padrones, 2015). Para Wernke (2005) os produtos consomem as atividades e é por essas atividades que incorrem os custos, por isso torna-se relevante a aplicação do $A B C$.

Nota-se que o método $A B C$ surgiu para melhorar a exatidão das informações, para isso são necessários alguns passos para a implementação desse método. $O$ primeiro é identificar as atividades relevantes dentro de cada departamento. O segundo é direcionar os custos para as atividades. $O$ terceiro é selecionar os direcionadores de custos e o quarto e último é atribuir os custos aos produtos e serviços (Martins, 2003).

\subsection{Estudos anteriores}

Como exemplo de pesquisas anteriores que abordaram a temática custos para servir pode-se citar Robles et al. (2005), Faria et al. (2010), Gensler et al. (2012), Fernandes et al. (2014) e Souza et al. (2019). Robles 
et al. (2005) elaboraram um estudo de caso em uma empresa do setor de tintas decorativas e identificaram os custos logísticos de distribuição utilizando a ferramenta dos custos para servir para aperfeiçoar os resultados da empresa. Após diversas entrevistas com os profissionais das áreas de controladoria, operação, logística vendas e marketing, os autores implantaram um modelo do Custeio Baseado em Atividades para a gestão dos custos para servir.

Faria et al. (2010) analisaram as atividades que podem ser desenvolvidas em nível multidimensional dentro de uma empresa de serviços logísticos. Para realizar as análises foram coletados dados sobre filiais, rotas e clientes que geram maior lucro para a empresa. Os autores constataram que a organização não controlava seus custos. Portanto, foram realizadas diversas análises para aperfeiçoar a gestão, uma das estratégias foi aplicar os custos para servir para o gestor encontrar a lucratividade por cliente.

Gensler et al. (2012) examinaram os determinantes dos custos para servir em uma instituição financeira e verificaram que $o$ atendimento on-line melhorou a lucratividade do cliente, aumentou as receitas com o cliente e diminui os custos com o atendimento. Evidências similares já haviam sido constatadas por Campbell e Frei (2010).

Fernandes et al. (2014) por meio de uma pesquisa-ação em uma empresa de administração condominial verificaram de que forma os custos para servir contribuem para gerar informações precisas e confiáveis para a organização, a fim de identificar os clientes mais rentáveis. Os resultados apontaram que os serviços prestados para os clientes eram cobrados igualmente. Após a pesquisa verificou-se que $60 \%$ dos clientes eram rentáveis e $40 \%$ eram não rentáveis. Assim, os autores concluíram que era preciso cobrar preços diferenciados.

Souza et al. (2019) realizaram uma pesquisa em uma empresa de software com o objetivo de identificar os clientes mais rentáveis. Verificou-se que $40 \%$ dos clientes geram $100 \%$ do lucro da empresa, $40 \%$ tinham rentabilidade intermediária e geravam $25 \%$ da lucratividade, enquanto os menos rentáveis representam os $25 \%$ do faturamento.

\section{PROCEDIMENTOS METODOLÓGICOS}

A pesquisa se classifica como descritiva, qualitativa e operacionalizada por meio de um estudo de caso. Ela foi aplicada em uma indústria de etiquetas personalizadas, denominada para este estudo de empresa Alfa. A empresa atende as necessidades das indústrias de confecções da região sul do Estado catarinense em relação ao fornecimento de acessórios como: etiquetas, cintos, tags e metais. A partir de um diagnóstico inicial observou-se que a indústria não possuía um departamento de custos formalizado e desconhecia os reais custos para atender seus clientes, bem como os resultados obtidos, o que motivou a aplicação do estudo.

Os dados coletados foram baseados nos históricos de venda e produção; fluxo do processo produtivo; controles de tempo por atividade; e documentos como: fluxo de caixa, faturamento, folha de pagamento e demais controles da organização; no período de setembro e outubro de 2018. Nesse mesmo período, foi realizada entrevista com o proprietário da empresa que auxiliou na identificação dos valores de aquisição, vida útil e valor residual dos bens de ativo imobilizado, entre outros dados.

O primeiro passo foi mapear o processo produtivo de etiquetas, produto que foi enfatizado nesse estudo tendo em vista sua representatividade nas vendas totais. Em seguida, para a aplicação da técnica custos para servir se utilizou o custeio $A B C$, por meio de levantamento das atividades que foram categorizadas em Administrativo, Comercial, Desenvolvimento e Produção; e da identificação dos gastos diretos e indiretos incorridos no período, bem como a definição dos direcionadores de recursos. Para distribuir os custos indiretos das atividades para os clientes selecionados no estudo foi desenvolvida uma planilha no intuito de cronometrar o tempo de realização das atividades para atender cada cliente, no período de 03/09/2018 a 31/10/2018. Após coletados, os dados foram tabulados em planilhas eletrônicas da Microsoft Excel para análise dos custos para servir os principais clientes e os resultados, considerando os valores médios dos meses de setembro e outubro de 2018.

Cabe destacar que nesse estudo foram enfocados os três clientes mais representativos em relação ao faturamento do ano anterior ao estudo (2017). 


\section{APRESENTAÇÃO E ANÁLISE DOS RESULTADOS}

\subsection{Caracterização da empresa e do processo produtivo}

A organização em estudo foi fundada no ano de 2005, o quadro societário é composto por apenas um sócio e o regime de tributação adotado é o Simples Nacional. Localizada no sul do estado de Santa Catarina, a organização atua principalmente na produção por encomenda de artigos e acessórios para o setor de vestuário, tais como: etiquetas, cintos, tag e metal. O produto mais vendido pela empresa em 2017 foi a etiqueta, que representou $51,86 \%$ das vendas nesse ano. Dessa forma, esse estudo focaliza o custo de fabricação desse produto para atender os três principais clientes.

A carteira de clientes da empresa totaliza aproximadamente cem indústrias do vestuário e as principais são confecções de grande porte também localizadas na região, tendo em vista que esse segmento econômico representa um dos mais significativos para o sul catarinense. Atualmente, a Alfa possui uma área total própria de $750 \mathrm{~m}^{2}$ e 10 funcionários, que são alocadas na área produtiva (cinco), no setor de desenvolvimento de produtos (dois), nas áreas comercial (dois) e administrativa (um). O processo produtivo da etiqueta é realizado conforme ilustração na Figura 1.

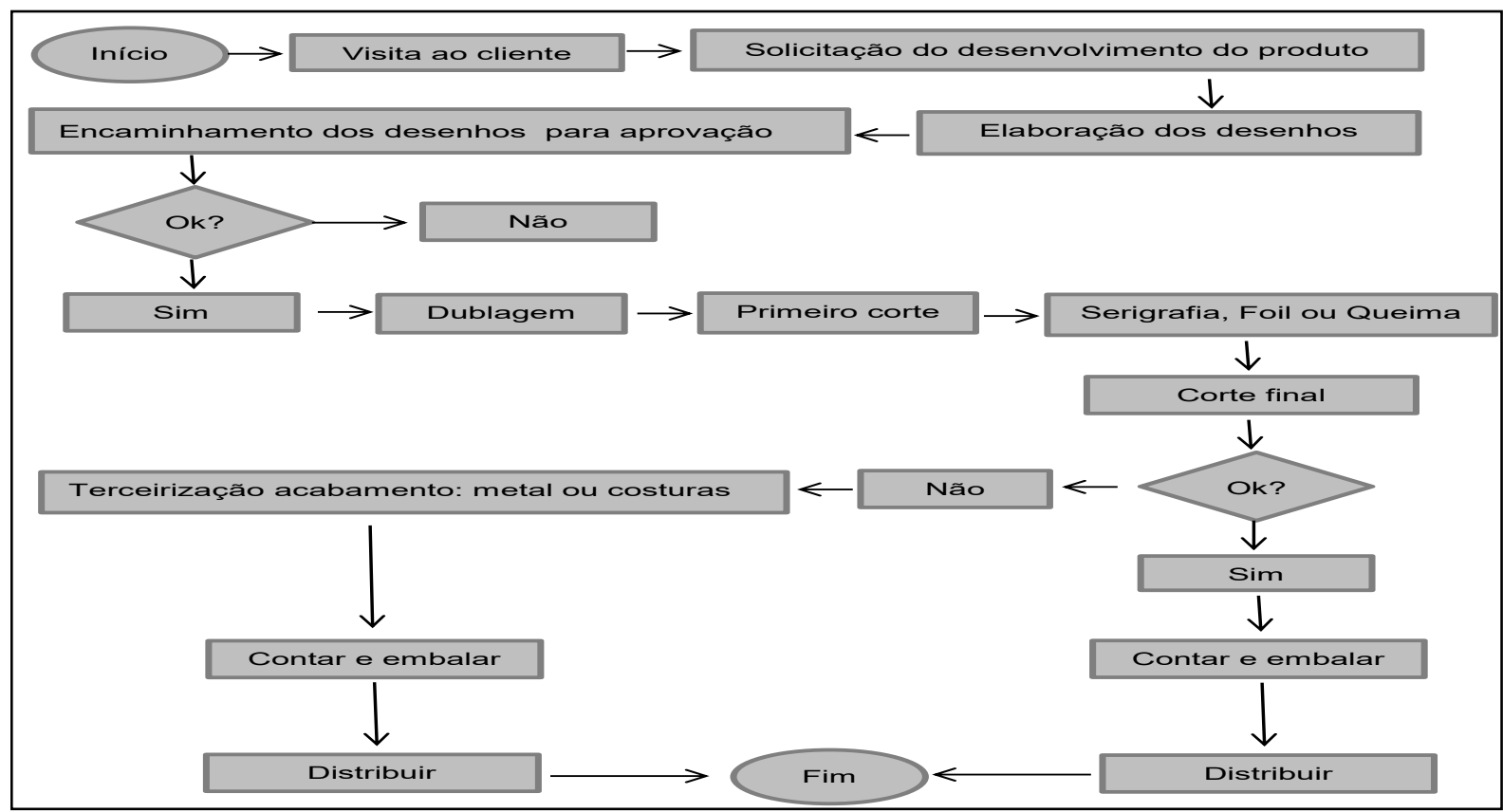

Figura 1- Fluxograma do processo produtivo.

Fonte: Elaborada pelos autores (2020)

O processo produtivo das etiquetas inicia com a visita dos vendedores aos clientes ou pelo contato do cliente com os vendedores para solicitar o desenvolvimento de um novo produto. Em seguida, os vendedores passam a solicitação do cliente para o setor de desenvolvimento, que desenhará os produtos conforme as especificações solicitadas.

Após a execução do desenho, este é encaminhado para o cliente para fazer a aprovação do pedido ou não. Caso o cliente aprove o desenho se inicia o processo produtivo com a emissão de ordem de compra dos materiais necessários (couro ou sintético). O processo de compra é realizado pelo gerente de produção, a empresa conta com aproximadamente 25 fornecedores e todas as compras são realizadas por e-mail. Em seguida, é desenvolvido o fotolito, que é um filme transparente, que serve como matriz para impressão, sendo que esse é confeccionado sempre em cor preta. O papel filme é exposto à luz por um determinado tempo, que possibilita que as imagens do fotolito sejam impressas na chapa, essa etapa é denominada de gravação.

Realizadas as etapas anteriores a próxima fase é a de dublagem, que consiste na colocação de dois materiais acoplados um no outro para aumentar a espessura da etiqueta, a deixando mais firme. Na sequência, 
é efetuado o primeiro corte, dependendo do acabamento a etiqueta pode ir para: i) serigrafia, processo em que é gravado a marca do cliente em uma tela para impressão manual da gravura; ii) foil, que é um papel fino com características metálicas e com cor, a aplicação é feita com uma matriz (marca do cliente) no sintético, sua finalidade é fazer baixo relevo com cor na etiqueta; iii) queima (sem papel) sua função é a mesma do foil, porém a etiqueta permanece na mesma cor.

Por fim, é realizado o último corte para finalizar o acabamento, sendo necessário levar os produtos a uma empresa terceirizada para fins de acabamentos como: colocação de metal, costura, controle de qualidade e contagem, pois a empresa Alfa não realiza esses processos. Finalizados esses processos é efetuada a entrega das etiquetas pelos vendedores, sendo que cada vendedor é responsável em entregar o pedido aos seus clientes. Nos casos, em que, os produtos são distribuídos por transportadora, o vendedor também é responsável por tal atividade.

Como os produtos são personalizados, ou seja, para cada venda ocorre a personalização das etiquetas conforme as especificações dos clientes, o preço de venda sofre oscilações levando em consideração os custos que serão necessários para produzi-las. Destaca-se que devido ao porte da organização, esta não possui área de custos formalizada e sistemas de informações gerenciais para suporte da gestão. O gestor faz uso apenas do custeio variável para cálculo dos custos dos produtos, não alocando os custos indiretos que também impactam no resultado da empresa. Assim, para identificar os custos o gerente de produção utiliza uma planilha eletrônica e calcula o preço de venda adicionando os tributos sobre venda, margem de lucro desejada, gastos com terceiros, serigrafia, foil, matriz e embalagem.

\subsection{Identificação dos custos para servir por meio do custeio ABC}

De acordo informações financeiras obtido dos documentos analisados, a empresa Alfa possui aproximadamente 100 clientes, sendo que os clientes denominados nesse estudo de $A, B$ e C foram os mais representativos no faturamento no ano de 2017, correspondendo a $30 \%$ das vendas. Os clientes D, E e F representaram $15 \%$ do faturamento e os demais corresponderam a $55 \%$ das vendas nesse período. Esses dados são apresentados na Tabela 1.

\begin{tabular}{ccc}
\hline Cliente & Valor em R\$ & Valor em \% \\
\hline A & $\mathrm{R} \$ 230.628,25$ & $13 \%$ \\
$\mathrm{~B}$ & $\mathrm{R} \$ 167.250,49$ & $10 \%$ \\
$\mathrm{C}$ & $\mathrm{R} \$ 129.984,06$ & $7 \%$ \\
$\mathrm{D}$ & $\mathrm{R} \$ 112.306,23$ & $6 \%$ \\
$\mathrm{E}$ & $\mathrm{R} \$ 87.432,44$ & $5 \%$ \\
$\mathrm{~F}$ & $\mathrm{R} \$ 79.210,75$ & $4 \%$ \\
Outros & $\mathrm{R} \$ 993.723,20$ & $55 \%$ \\
\hline Total & $\mathbf{R} \$ \mathbf{1 . 8 0 0 . 5 3 5 , 4 2}$ & $\mathbf{1 0 0 \%}$ \\
\hline
\end{tabular}

Tabela 1. Vendas por clientes em 2017

Fonte: Elaborada pelos autores (2020);

Após identificar os três principais clientes da empresa Alfa, se iniciou a aplicação do Custeio $A B C$ no intuito de identificar o resultado para servi-los. Assim, na sequência, se buscou identificar as atividades realizadas na organização que abrangem os processos de pré-venda e pós-venda e foram agrupadas em quatro categorias: 1) Administrativo; 2) Comercial; 3) Desenvolvimento; e 4) Produção. A Tabela 2 apresenta a descrição dessas atividades: 


\begin{tabular}{|c|c|c|c|}
\hline $\begin{array}{l}\text { Grupos de } \\
\text { Atividades }\end{array}$ & Atividades & $\begin{array}{l}\text { Grupos de } \\
\text { Atividades }\end{array}$ & Atividades \\
\hline \multirow{6}{*}{ 1. Administrativo } & Contas a receber & \multirow{4}{*}{$\begin{array}{l}3 . \\
\text { Desenvolvimento }\end{array}$} & Desenho de produtos \\
\hline & Contas a pagar & & Pedido de metal \\
\hline & Tesouraria & & Pedido de etiqueta interna \\
\hline & Emissão de nota fiscal & & $\begin{array}{l}\text { Desenvolvimento } \\
\text { mostruário }\end{array}$ \\
\hline & Emissão de boletos & \multirow{10}{*}{ 4. Produção } & $\begin{array}{l}\text { Emissão de ordem de } \\
\text { produção }\end{array}$ \\
\hline & Operações bancárias & & Compra dos materiais \\
\hline \multirow{8}{*}{ 2. Comercial } & Visita ao cliente & & Fotolito \\
\hline & Venda de produtos & & Enfesto \\
\hline & Emissão de pedidos & & Gravação \\
\hline & $\begin{array}{l}\text { Encaminhamento de produtos para } \\
\text { beneficiamento de terceiro }\end{array}$ & & Dublagem \\
\hline & Distribuição e entrega do produto & & Corte \\
\hline & \multirow{3}{*}{$\begin{array}{l}\text { Cobrança de pagamentos em } \\
\text { cheque/dinheiro }\end{array}$} & & Serigrafia \\
\hline & & & Queima \\
\hline & & & Foil \\
\hline
\end{tabular}

Tabela 2. Descrição das atividades

Fonte: Elaborada pelos autores (2020)

Em seguida, foram identificados os recursos consumidos e definidos os direcionadores de recursos conforme a utilização em cada atividade. A tabela 3 expõe os custos indiretos identificados na organização e seus direcionadores que foram estabelecidos conforme estudo na empresa.

\begin{tabular}{|c|c|c|c|c|c|}
\hline \multicolumn{6}{|c|}{ Atividades } \\
\hline Recursos & Direcionadores & 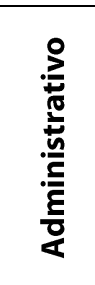 & 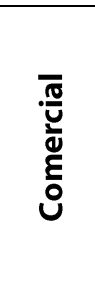 & 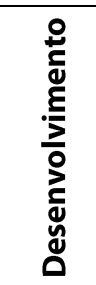 & 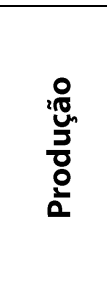 \\
\hline ACII - Associação empresarial de Içara & Diretamente & $100 \%$ & & & \\
\hline Água & Utilização da área - m2 & 34,55 & 29,55 & 34,55 & 356,25 \\
\hline Alvará e IPTU & Utilização da área - m2 & 34,55 & 29,55 & 34,55 & 356,25 \\
\hline Combustível & Diretamente & & $100 \%$ & & \\
\hline Comissão representantes & Diretamente & & $100 \%$ & & \\
\hline Contabilidade & Diretamente & $100 \%$ & & & \\
\hline Depreciação de computadores & Número de computadores & 1 & 1 & 2 & 1 \\
\hline Depreciação de móveis e utensílios & Quantidade usada & 5 & 8 & 7 & 4 \\
\hline Depreciação máquinas & Diretamente & & & & $100 \%$ \\
\hline Depreciação pavilhão & Utilização da área - m2 & 34,55 & 29,55 & 34,55 & 356,25 \\
\hline Despesa bancária & Diretamente & $100 \%$ & & & \\
\hline Gasto com Software & Diretamente & $100 \%$ & & & \\
\hline Internet & $\begin{array}{l}\text { Número de computadores } \\
\text { com acesso à internet }\end{array}$ & 1 & 1 & 2 & 1 \\
\hline Manutenção de veículo & Diretamente & & $100 \%$ & & \\
\hline Material de limpeza & Utilização da área - m2 & 34,55 & 29,55 & 34,55 & 356,25 \\
\hline Salários com encargos e Pró-labore & Total de pessoal & 1 & 2 & 2 & 5 \\
\hline Seguro & Utilização da área - m2 & 34,55 & 29,55 & 34,55 & 356,25 \\
\hline Telefone & Número aparelhos & 2 & 1 & 2 & 1 \\
\hline Vigilância & Utilização da área - m2 & 34,55 & 29,55 & 34,55 & 356,25 \\
\hline
\end{tabular}

Tabela 3. Definição e direcionadores de recursos.

Fonte: Elaborada pelos autores (2020) 
Destaca-se que a Alfa não possui nenhum veículo, mas ela arca com os custos de combustível e manutenção dos veículos utilizados na atividade Comercial que também apresenta gastos com comissão. Os serviços de contabilidade, mensalidade do software, contribuição ACIl e as despesas bancárias são vinculados diretamente à atividade Administrativo. A depreciação de máquinas foi distribuída somente para a produção, pois as máquinas são utilizadas no processo produtivo. Os outros recursos foram alocados para todas as quatro atividades: 1) Administrativo; 2) Comercial; 3) Desenvolvimento; e 4) Produção.

Para o levantamento dos custos indiretos fez-se uso dos documentos da empresa e obtidos com o auxílio do proprietário na identificação do valor dos bens de ativo imobilizado, vida útil e valor residual. 0 método de cálculo da depreciação foi o linear. Segundo o proprietário sua intenção é utilizar os bens até o final da vida útil, dessa forma o valor residual foi considerado igual a zero. Apresentam-se na sequência os valores de depreciação para a organização em estudo.

\begin{tabular}{|c|c|c|c|c|}
\hline Tipo & Valor & Valor depreciável & Vida útil(ano) & Depreciação (ao mês) \\
\hline \multicolumn{5}{|l|}{ Imóvel } \\
\hline Galpão & $431.980,97$ & $431.980,97$ & 60 & 599,97 \\
\hline \multicolumn{5}{|l|}{ Máquinas } \\
\hline 1 enfesto & $2.000,00$ & $2.000,00$ & 15 & 11,11 \\
\hline 1 balancim & $15.000,00$ & $15.000,00$ & 15 & 83,33 \\
\hline 3 prensas & $12.000,00$ & $12.000,00$ & 15 & 66,67 \\
\hline 1 frequência & $20.000,00$ & $20.000,00$ & 15 & 111,11 \\
\hline 1 corte vinco & $8.000,00$ & $8.000,00$ & 15 & 44,44 \\
\hline 1 impressora automática & $5.000,00$ & $5.000,00$ & 15 & 27,78 \\
\hline 2 garras (manual) & $10.000,00$ & $10.000,00$ & 15 & 55,56 \\
\hline 1 offset tag & $65.000,00$ & $65.000,00$ & 15 & 361,11 \\
\hline 1 guilhotina tag & $15.000,00$ & $15.000,00$ & 15 & 83,33 \\
\hline \multicolumn{5}{|l|}{ Computador e Impressora } \\
\hline $\begin{array}{l}3 \text { computadores e } \\
3 \text { impressoras }\end{array}$ & $7.927,00$ & $7.927,00$ & 10 & 66,06 \\
\hline 2 notebooks & $4.127,90$ & $4.127,90$ & 10 & 34,40 \\
\hline \multicolumn{5}{|l|}{ Móveis e utensílios } \\
\hline 11 cadeiras & $1.097,14$ & $1.097,14$ & 10 & 9,14 \\
\hline 9 mesas & $2.484,00$ & $2.484,00$ & 15 & 13,80 \\
\hline 4 armários & $2.067,60$ & $2.067,60$ & 10 & 17,23 \\
\hline Total & $601.684,61$ & $601.684,61$ & & $1.585,05$ \\
\hline
\end{tabular}

Tabela 4. Valor da depreciação.

Fonte: Dados da pesquisa (2020)

Nota-se que o valor mensal da depreciação totalizou $\mathrm{R} \$ 1.585,05$ que considerou as depreciações dos materiais, computador e impressora, máquinas e imóveis. O galpão foi o bem que sofreu maior depreciação devido ao seu custo de aquisição $(599,97)$, tendo sido considerada a estimação para fins gerenciais, diferente daquelas utilizadas para fins da legislação tributária. As máquinas e equipamentos tiveram depreciação correspondente a R\$ 844,44 ao mês. Os demais bens apresentaram valores de depreciação menos significativos. As escolhas quanto a depreciação se justifica pelo regime tributário ao que a empresa em estudo está submetida e por esta análise se tratar de estratégias gerenciais.

Na Tabela 5, estão evidenciados os valores de salários e encargos para cada categoria de atividades. A área administrativa possui apenas um funcionário; a comercial e o desenvolvimento possuem dois funcionários cada; e, na produção trabalham quatro funcionários, além de um gerente de produção. 


\begin{tabular}{l|c|c|r}
\hline \multicolumn{1}{c|}{ Salários e encargos } & Setembro & Outubro & \multicolumn{1}{c}{ Média } \\
\hline Administrativo & $1.592,12$ & $1.592,12$ & $1.592,12$ \\
\hline Comercial & $15.898,88$ & $19.745,86$ & $17.822,37$ \\
\hline Desenvolvimento & $5.463,73$ & $5.938,44$ & $5.701,08$ \\
\hline Produção & $7.696,24$ & $6.988,64$ & $7.342,44$ \\
\hline Gerente de produção & $3.366,11$ & $3.412,18$ & $3.389,14$ \\
\hline Total & $34.017,07$ & $37.677,23$ & $35.847,15$ \\
\hline
\end{tabular}

Tabela 5. Salários e encargos

Fonte: Dados da pesquisa (2020)

Observa-se que a média salarial totalizou $\mathrm{R} \$ 35.847,15$ no período pesquisado, sendo que a atividade Comercial consumiu aproximadamente $50 \%$ desse recurso, pois além dos salários e encargos se tem comissões dos vendedores. Na Tabela 6, são apresentados o valor médio dos custos indiretos dos meses de setembro e outubro de 2018 e a distribuição para as atividades realizadas pela empresa, conforme os direcionadores expostos na Tabela 3.

\begin{tabular}{|c|c|c|c|c|c|}
\hline \multicolumn{6}{|c|}{ ATIVIDADES } \\
\hline RECURSOS & Valor em R\$ & 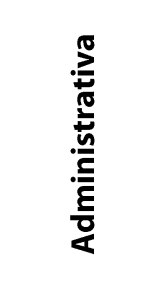 & 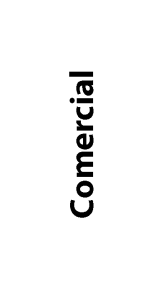 & 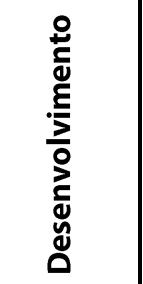 & 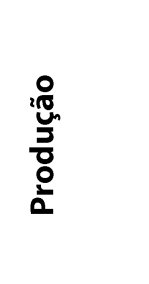 \\
\hline \multicolumn{6}{|l|}{ Gastos Indiretos } \\
\hline ACII - Associação empresarial & 47,16 & 47,16 & & & \\
\hline Água & 81,33 & 6,18 & 5,28 & 6,18 & 63,69 \\
\hline Alvará e IPTU & 256,81 & 19,50 & 16,68 & 19,50 & 201,12 \\
\hline Combustível & $3.713,82$ & & $3.713,82$ & & \\
\hline Comissão representantes & $9.834,97$ & & $9.834,97$ & & \\
\hline Contabilidade & $1.028,50$ & $1.028,50$ & & & \\
\hline Depreciação das máquinas & 844,44 & & & & 844,44 \\
\hline Depreciação de computadores & 100,46 & 20,09 & 20,09 & 40,18 & 20,09 \\
\hline Depreciação de móveis e utensílios & 40,17 & 8,37 & 13,39 & 11,72 & 6,70 \\
\hline Depreciação pavilhão & 599,97 & 45,57 & 38,97 & 45,57 & 469,86 \\
\hline Despesas bancárias & $6.592,68$ & $6.592,68$ & & & \\
\hline Energia elétrica & 615,63 & 46,76 & 39,99 & 46,76 & 482,12 \\
\hline Gasto com software & 375,26 & 375,26 & & & \\
\hline Internet & 55,33 & 11,07 & 11,07 & 22,13 & 11,07 \\
\hline Manutenção de veículo & $1.705,21$ & & $1.705,21$ & & \\
\hline Material/Serviço de limpeza & 402,95 & 30,60 & 26,18 & 30,60 & 315,57 \\
\hline Salários com encargos e Pró-labore & $35.847,15$ & $1.592,12$ & $17.822,37$ & $5.701,08$ & $10.731,58$ \\
\hline Seguro & 381,59 & 28,9 & 24,79 & 28,98 & 298,84 \\
\hline Telefone & 588,16 & 196,05 & 98,03 & 196,05 & 98,03 \\
\hline Vigilância & 495,00 & 37,60 & 32,15 & 37,60 & 387,65 \\
\hline Total & $63.606,58$ & $10.086,48$ & $33.402,98$ & $6.186,36$ & $13.930,75$ \\
\hline
\end{tabular}

Tabela 6. Definição dos gastos indiretos

Fonte: Dados da pesquisa (2020)

Os custos mais significativos se referem aos salários com encargos e pró-labore, que representaram $55,88 \%$ sobre os custos indiretos totais; seguido das comissões que atingiram $15,33 \%$ e as despesas bancárias que somaram $10,28 \%$. O restante dos gastos indiretos totalizou $28,79 \%$. 
Verifica-se que a atividade Comercial é a que mais requer recursos, representando $53 \%$ dos custos indiretos mensais; em seguida tem-se a Produção com 22\% desses gastos; a atividade Administrativo que correspondeu a 16\%; e a atividade Desenvolvimento, que representou 10\% dos gastos indiretos totais.

A Tabela 7 mostra o resultado da alocação dos custos das atividades para os clientes $A, B$ e $C$ conforme o tempo despendido para atendê-los, o qual foi cronometrado nos meses em estudo pelos responsáveis de cada área. Observa-se que o valor restante foi direcionado para o grupo Outros.

\begin{tabular}{|c|c|c|c|c|c|}
\hline Atividades & $\begin{array}{c}\text { Custo indireto } \\
\text { total }\end{array}$ & Cliente A & Cliente B & Cliente C & Outros \\
\hline 1. Administrativo & $10.086,48$ & 783,52 & 648,69 & 178,07 & $8.476,21$ \\
\hline 1.1 Contas a receber & $4.408,54$ & 661,41 & 483,34 & 165,35 & $3.098,45$ \\
\hline 1.2 Contas a pagar & $3.879,42$ & & & & $3.879,42$ \\
\hline 1.3 Tesouraria & 480,79 & & & & 480,79 \\
\hline 1.4 Emissão de Nota Fiscal & 277,28 & 83,95 & 80,13 & 12,72 & 100,48 \\
\hline 1.5 Emissão de boleto & 282,37 & 38,16 & 85,22 & & 158,99 \\
\hline 1.6 Banco & 758,08 & & & & 758,08 \\
\hline 2. Comercial & $33.402,98$ & $1.756,31$ & $2.007,50$ & $2.718,42$ & $26.920,74$ \\
\hline 2.1 Visita Cliente (deslocamento) & $14.065,18$ & 568,33 & 659,99 & $1.404,32$ & $11.432,55$ \\
\hline 2.2 Venda de produtos & $7.138,92$ & 366,66 & 334,99 & 712,78 & $5.724,50$ \\
\hline 2.3 Emissão pedidos & $1.932,31$ & 124,67 & 102,67 & 55,00 & $1.649,98$ \\
\hline 2.4 Distribuição produtos & $3.222,97$ & 330,00 & 348,33 & - & $2.544,64$ \\
\hline 2.5 Entrega produtos & $5.195,61$ & 366,66 & 561,53 & 179,66 & $4.087,76$ \\
\hline 2.6 Cobrança cheque/dinheiro & $1.847,98$ & & & 366,66 & $1.481,32$ \\
\hline 3. Desenvolvimento & $6.186,36$ & 329,23 & 956,05 & $1.016,46$ & $3.884,61$ \\
\hline 3.1 Desenho de produtos & $5.082,63$ & 306,86 & 920,57 & $1.016,46$ & $2.838,74$ \\
\hline 3.2 Pedido etiqueta interna & 195,94 & - & - & - & 195,94 \\
\hline 3.3 Pedido metal & 907,78 & 22,37 & 35,48 & - & 849,93 \\
\hline 4. Produção & $13.930,75$ & 857,12 & 538,29 & 671,19 & $11.864,15$ \\
\hline 4.1 Emissão ordem de produção & 419,49 & 11,19 & 57,05 & 38,03 & 313,22 \\
\hline 4.2 Compra de materiais & 111,86 & 1,58 & 6,71 & 33,56 & 70,02 \\
\hline 4.3 Fotolito & 270,71 & - & - & 8,95 & 261,76 \\
\hline 4.4 Gravação & 829,14 & 33,56 & 20,14 & 20,14 & 755,31 \\
\hline 4.5 Dublagem & 485,94 & 58,17 & 8,95 & 20,14 & 398,69 \\
\hline 4.6 Corte & $4.013,49$ & 161,09 & 114,10 & 255,05 & $3.483,25$ \\
\hline 4.7 Serigrafia & $1.949,58$ & 103,14 & 23,49 & 93,97 & $1.728,98$ \\
\hline 4.8 Queima & $2.373,55$ & 181,22 & 106,94 & 8,95 & $2.076,44$ \\
\hline 4.9 Foil & $1.517,56$ & 150,57 & 82,33 & 31,32 & $1.253,33$ \\
\hline 4.1.0 Enfesto & $1.959,42$ & 156,61 & 118,58 & 161,09 & $1.523,15$ \\
\hline Total & $63.606,58$ & $3.726,18$ & $4.150,54$ & $4.584,14$ & $51.145,72$ \\
\hline
\end{tabular}

Tabela 7. Alocação dos gastos indiretos para os clientes

Fonte: Dados da pesquisa (2020)

Percebe-se que a atividade Administrativo apresentou mais custo na tarefa Contas a Receber para o Cliente $A(15 \%)$, tendo em vista que esse exige maior tempo para cobrança. Na área Comercial o destaque foi para o Cliente $C(8 \%)$, seguido do cliente B (6\%), devido à localização destes que demanda mais tempo e recursos para locomoção. Do mesmo modo, a atividade de Desenvolvimento destinou mais tempo, nesse período, aos clientes C (16\%) e B (15\%), em virtude dos desenhos dos produtos.

As atividades de Produção concentraram seus esforços para atender, sobretudo, o cliente $A$, sendo que os outros dois estavam em fase de desenvolvimento e aprovação de produtos. Com base nesses resultados é possível inferir que no período investigado as atividades Administrativo e de Produção estavam concentradas para atender o Cliente A (6\%), que em tese, já havia efetuado os pedidos e a compra das etiquetas; enquanto as atividades Comerciais e de Desenvolvimento enfocavam seus esforços para as vendas e desenvolvimento de produtos. 
Nota-se uma importante limitação da pesquisa em relação ao período de coleta dos dados que foi realizada em apenas dois meses (setembro e outubro). Cabe observar que a indústria do vestuário apresenta especificidades no que se refere ao desenvolvimento de coleções (verão, alto verão, inverno e alto inverno) e à produção das peças. Assim, para obter um resultado mais preciso seria necessário ampliar o período de coleta de dados para doze meses, de modo a contemplar as questões inerentes à sazonalidade.

Além disso, no Administrativo não foi possível mensurar os tempos precisos para atender os clientes A, B e C para as seguintes tarefas: contas a pagar, tesouraria e banco, tendo em vista que não são específicas para cada cliente. Assim, os custos dessas atividades foram alocados para o grupo Outros. Observa-se que para o cliente $C$ não foi realizada a emissão de boletos, pois os pagamentos são efetuados a vista.

$\mathrm{Na}$ atividade Comercial não ocorreu distribuição dos produtos para cliente $\mathrm{C}$ no período, pois este retirou na empresa terceirizada. Na atividade de Desenvolvimento nenhum dos três principais clientes fez pedido de etiqueta interna, logo esse custo foi alocado para o grupo Outros. Na Atividade de Produção o fotolito também não foi desenvolvido para os clientes $A$ e $B$, pois já tinham sido realizados em meses anteriores.

Assim, ao analisar os custos indiretos totais verificou-se que os gastos para atender o cliente $C$ representaram 7,21\%; o cliente B consumiu 6,53\%; o cliente $A$ teve um custo de 5,86\% em relação ao total; e a categoria outros representou $80,41 \%$. Destaca-se que outra limitação de pesquisa foi a definição dos principais clientes da empresa com base no faturamento do ano de 2017, que corresponderam a $30 \%$ das vendas. Contudo, no ano de 2018 essa situação não se repetiu, tendo em vista a crise econômica, que também atingiu o setor do vestuário, os Clientes selecionados representaram juntos apenas 12,35\% no período investigado.

Os custos diretos contemplam serviços terceirizados, materiais, entre outros. Os serviços terceirizados são os seguintes: furar, colocar remanche, costurar, colar e embalar as etiquetas, e foram identificados conforme as notas de prestação de serviços. O consumo dos materiais foi calculado de acordo com a quantidade usada para produção de etiquetas de cada cliente. Somente não ocorreu compra de matriz para o cliente $C$, pois foi possível reaproveita-la. A Tabela 8 apresentam-se os custos totais por cliente, que abrangem os custos indiretos e os custos diretos.

\begin{tabular}{l|r|r|r|r|r}
\hline Descrição & Cliente A & \multicolumn{1}{c|}{ Cliente B } & \multicolumn{1}{c|}{ Cliente C } & \multicolumn{1}{c}{ Outros } & Total Geral \\
\hline Gastos Indiretos das atividades & $3.726,18$ & $4.150,54$ & $4.584,14$ & $51.145,72$ & $63.606,58$ \\
\hline Gastos Diretos & $4.056,93$ & $1.646,55$ & $1.244,87$ & $27.069,73$ & $34.018,08$ \\
\hline Serviços de terceiros para produção & 418,17 & 450,94 & 219,09 & $2.812,37$ & 3900,57 \\
\hline Material & 999,97 & 514,96 & 811,16 & $18.426,02$ & 20752,11 \\
\hline Matriz & 177,5 & 303,5 & - & $2.367,59$ & 2848,59 \\
\hline Metal & $2.461,29$ & 377,15 & 214,63 & $3.463,75$ & $6.516,82$ \\
\hline Custo Total & $7.783,10$ & $5.797,09$ & $5.829,01$ & $78.215,45$ & $97.624,65$ \\
\hline
\end{tabular}

Tabela 8. Custos indiretos e diretos

Fonte: Dados da pesquisa (2020)

Por meio da análise dos custos para servir se percebeu uma discrepância dos resultados entre o total dos custos diretos e indiretos para os três clientes pesquisados. Conforme destacado anteriormente, no período em estudo o Cliente A estava na fase de fabricação dos produtos, logo os custos diretos foram mais elevados, perfazendo $52 \%$ dos custos totais. Os clientes B e C a concentração do trabalho estava nas atividades Comercial e Desenvolvimento acarretando maiores custos indiretos nesse período, correspondentes a $72 \%$ e $79 \%$, respectivamente. Na análise do grupo Outros e no Total Geral verificou-se que a empresa apresenta custos indiretos relevantes, equivalentes à $65 \%$ em relação aos custos totais.

Esse achado chama a atenção para a necessidade de gerenciamento da estrutura fixa da organização em relação a sua demanda de vendas e produção, uma vez que quanto maior a utilização de sua capacidade produtiva melhor será o resultado pela diluição dos custos indiretos totais aos produtos fabricados. Esses resultados denotam a utilidade da metodologia custos para servir, pois fornece informações precisas e 
confiáveis (Fernandes et al., 2014). Assim, esses achados vão ao encontro do estudo se Souza et al. (2019), no qual os autores observaram que a lucratividade dos clientes se altera conforme a utilização da estrutura fixa, pois de acordo com a maior utilização dessa estrutura, menor o custo individual de cada atendimento.

\subsection{Análise da lucratividade}

Como a empresa Alfa trabalha com a fabricação de produtos por encomenda e atende o setor do vestuário que é muito específico, que tem foco na produção principalmente em quatro períodos no ano, suas vendas e custos diretos não apresentam um comportamento linear.

Observou-se redução das vendas médias do ano de 2017 para 2018, sendo que o cliente A que tinha participação de 13\% das vendas em 2017 no período investigado teve uma redução para 6\%; o cliente B diminuiu de $10 \%$ para $3 \%$; e o cliente $C$ apresentou queda de $7 \%$ para $4 \%$.

Tabela 9 apresenta a Demonstração do Resulto (DR) considerando os valores médios dos meses de setembro e outubro de 2018.

\begin{tabular}{l|r|r|r|r|r}
\hline Descrição & \multicolumn{1}{|c|}{ A } & \multicolumn{1}{c|}{ B } & \multicolumn{1}{c|}{ C } & \multicolumn{1}{c}{ Outros } & \multicolumn{1}{c}{ Total } \\
\hline Receita bruta de vendas & $9.182,59$ & $5.084,24$ & $5.365,67$ & $145.696,80$ & $165.329,30$ \\
\hline Vendas de Etiquetas & $7.695,16$ & $4.491,60$ & $4.404,00$ & $53.108,72$ & $69.699,48$ \\
\hline Vendas de outros produtos & $1.487,43$ & 592,64 & 961,67 & $92.588,08$ & $95.629,82$ \\
\hline (-) Simples Nacional (Indústria) $7,45 \%$ & 573,29 & 334,62 & 328,10 & $3.956,60$ & $5.192,61$ \\
\hline (-) Simples Nacional (Comércio) 6,95\% & 103,38 & 41,19 & 66,84 & $6.434,87$ & $6.646,27$ \\
\hline Receita Líquida & $8.505,92$ & $4.708,43$ & $4.970,74$ & $135.305,33$ & $153.490,41$ \\
\hline (-) Custo das etiquetas & $7.783,10$ & $5.797,09$ & $5.829,01$ & $78.215,45$ & $97.624,65$ \\
\hline (-) Custo de outros produtos & 578,50 & 148,16 & 371,18 & $42.262,22$ & $43.360,06$ \\
\hline Resultado Líquido & 144,32 & $-1.236,82$ & $-1.229,46$ & $14.827,66$ & $12.505,70$ \\
\hline
\end{tabular}

Tabela 9. Demonstração do resulto (DR)

Fonte: Dados da pesquisa (2020)

Percebeu-se que o resultado global da empresa foi positivo, perfazendo $7,56 \%$ da receita bruta de vendas. Contudo, os clientes B e C apresentaram prejuízo no período de, aproximadamente $10 \%$, devido a redução do faturamento e aos custos indiretos que se mantiveram, principalmente, nas atividades Comercial e Desenvolvimento. Esse fato acabou impactando o resultado global da organização que poderia ser maior.

Em uma análise com enfoque apenas no produto etiquetas foi possível perceber que as vendas apresentaram prejuízo no período, tanto na análise individual dos clientes como no resultado geral da empresa. Esse produto que representou em média $42 \%$ das vendas nos meses analisados incorreu em custo de aproximadamente $40 \%$ superior a receita bruta de vendas. Esse fato remete novamente a necessidade de gerenciamento da estrutura fixa da empresa em relação as demandas de vendas e produção ou a revisão do método de formação do preço de venda, uma vez que esses são elaborados apenas com base nos custos variáveis conforme foi destacado pelo proprietário. Esses resultados convergem com as constatações do estudo de Faria et al. (2010), que destacou que a empresa objeto de estudo poderia utilizar das informações obtidas no estudo para melhoria dos processos, revisão dos preços de vendas, entre outras decisões, tendo em vista a melhoria da lucratividade global da organização.

Cabe destacar ainda, que devido às especificidades das empresas que trabalham com o sistema de custos por ordem ou encomenda que a análise e gerenciamento dos custos deve abranger todas as atividades, desde as relacionadas à pré-venda, desenvolvimento de produtos, produção e pós-venda, além do período desses processos. Essas pontuações são congruentes com (Souza et al., 2006; Souza et al., 2008).

\section{CONSIDERAÇÕES FINAIS}

O estudo teve por objetivo, evidenciar o resultado dos principais clientes de uma indústria de etiquetas personalizadas com a aplicação dos custos para servir. Verificou-se que o processo produtivo da empresa ocorre em diversas etapas, as quais foram classificadas em quatro grupos de atividades: 
Administrativo, Comercial, Desenvolvimento e Produção. Com a aplicação do Custeio ABC verificou-se que as atividades Comercial e Produção são as que consumiram mais recursos, representando $53 \%$ e $22 \%$, respectivamente, dos custos indiretos mensais. Os custos mais significativos são os salários com encargos e pró-labore, que representaram aproximadamente $56 \%$ sobre os custos indiretos totais; seguido das comissões que atingiram $15 \%$.

Ao analisar os custos totais se constatou que o resultado para atender o cliente $A$ e os Outros foi positivo. Em relação aos clientes $B$ e $C$ a empresa obteve um resultado negativo, devido ao esforço para atendêlos, sobretudo, nas atividades Comercial e Desenvolvimento. A partir das informações sobre o resultado dos clientes a empresa conseguirá tomar as decisões adequadas, como estratégia de marketing, vendas e busca de novos clientes, principalmente, para cobrir seus custos indiretos que se mostraram mais representativos nesse período em estudo.

Verificou-se como limitações da pesquisa a falta de interesse dos funcionários em registrar o os tempos requeridos para o desenvolvimento das atividades, sendo necessário realizar acompanhamento diário para que esses dados fossem informados corretamente. Os três clientes que foram selecionadas para a pesquisa com base no faturamento no ano de 2017 apresentaram redução no ano de 2018. Isso ocorreu devido à instabilidade do mercado do vestuário e refletiu na diminuição dos pedidos desses clientes, fato que exigiu que a empresa Alfa prospectasse novos clientes para se manter.

O período de coleta dos dados, que compreendeu dois meses, não foi suficiente para que o estudo apresentasse um resultado mais preciso devido às particularidades da indústria de etiqueta pesquisada que adota o sistema de custos por ordem ou encomenda, assim para desenvolver, fabricar e distribuir seus produtos necessita de um período superior a um mês. Para o cálculo do custo com depreciação tomou-se como base as informações disponibilizadas pelo proprietário da empresa, que de certa forma, resultou em valores aproximados. O ideal seria realizar o teste de recuperabilidade antes do início dos cálculos a fim de gerar valores mais fidedignos. Outra limitação se referiu a impossibilidade de elaborar a Curva da Baleia, tendo em vista que a amostra contemplou apenas os três principais clientes da organização.

Apesar das limitações encontradas no decorrer da pesquisa, o estudo revelou algumas informações que o proprietário desconhecia, como por exemplo que o atendimento aos clientes $\mathrm{B}$ e $\mathrm{C}$ resultaram em prejuízo no período da pesquisa, bem como as vendas do principal produto da empresa as etiquetas personalizadas e que as despesas bancárias é o terceiro gasto indireto mais representativo para a empresa.

A pesquisa gerou implicações práticas, pois, com base nos resultados o proprietário adotou política de vendas que passou a exigir quantidade mínima de pedido por cliente no intuito de tornar as vendas mais lucrativas. Possibilitou o conhecimento dos custos indiretos vinculados ao atendimento dos clientes, informação importante para o processo decisório e, principalmente, para a formação do preço de venda.

No campo teórico sugere-se que, dependendo da atividade empresarial, a análise de custos não pode ocorrer somente em períodos mensais, em específico, nas empresas que trabalham pelo sistema de custos por encomenda e que têm a concentração de maiores valores de custos indiretos nas fases de pré-venda e desenvolvimento de produtos, enquanto que os custos diretos são mais representativos na fase de produção.

Conclui-se que as técnicas mais avançadas como os custos para servir contribuem muito para a gestão dos negócios. Entretanto, ainda há inúmeros desafios a serem superados, sobretudo em empresas de menor porte, como falta de preparado das pessoas. Essa prática requer mudança cultural na organização, sendo necessário explicar a importância do apontamento dos dados de produção às pessoas envolvidas, visando seu comprometimento para geração de informação gerencial correta, conforme salientaram Faria et al. (2010).

Para futuras pesquisas sugere-se ampliar o tempo de coleta de dados, além de realizar mais pesquisas no mercado que a empresa está inserida, aplicando o método $A B C$, para poder comparar os resultados e aprimorar a gestão do ramo de indústria de etiquetas personalizadas e acessórios para as empresas de confecções.

\section{REFERÊNCIAS}

Atkinson, A. A., Kaplan, R. S., Matsumura, E. M., \& Young, S. M. (2015). Contabilidade Gerencial: informação para tomada de decisão e execução da estratégia. São Paulo: Atlas. 
Becker, M., Monteiro, J. J., Castanha, E. T., \& Cittadin, A. (2020). Custos no cultivo do tabaco: um estudo em uma pequena propriedade rural do sul catarinense. Navus-Revista de Gestão e Tecnologia, 10, 01-16.

Blocher, E. J., Stout, D. E., \& Cokins, G. (2010). Cost management: A strategic emphasis. Includes index. New York: McGraw Hill.

Braithwaite, A.; Samakh, E. (1998). The cost-to-serve method. International Journal of Logistics Management, 9(1), 69-84.

Campbell, D., \& Frei, F. (2010). Cost structure, customer profitability, and retention implications of self-service distribution channels: Evidence from customer behavior in an online banking channel. Management Science, 56(1), 4-24.

Cokins, G. (2006). Measuring customer value: how BPM supports better marketing decisions. Business Performance management magazine, 4(1), 13-18.

Cooper, R.; Kaplan, R. S. (1991). The design of cost management systems: text, cases, and readings. Prentice Hall.

Cunha, P. M., Castanha, E. T., Monteiro, J. J., Vieira, A. C. P., \& Cittadin, A. (2018). O Uso do Custeio Variável para Gestão de uma Vinícola de Santa Catarina, Brasil. ABCustos, 13(2).

Faria, A. C., Borinelli, M. L., \& Mantovani, N. (2010). Análises multidimensionais e o conceito do custo para servir em empresas de serviços logísticos: Uma pesquisa-ação. Revista de Contabilidade e Organizações, 4(9), 126-144.

Faria, A. C. D., \& Costa, M. D. F. G. D. (2005). Gestão de custos logísticos. São Paulo: Atlas.

Fernandes, M. G., Faria, A. C., Crispim, S. F., Fernandes, F. C. (2014). Custo para servir clientes: uma pesquisaação em administração condominial na Baixada Santista (SP). Enfoque: Reflexão Contábil, 33(3), 1-19.

Ferreira, J. A. S. (2007). Contabilidade de custos. São Paulo: Pearson Prentice Hall.

Freeman, B., Haasz, S., Lizzola, S., \& Seiersen, N. (2000). Managing your cost-to-serve. Supply Chain Forum: An International Journal, 1(1), 18-28

Gensler, S., Leeflang, P., \& Skiera, B. (2012). Impact of online channel use on customer revenues and costs to serve: Considering product portfolios and self-selection. International Journal of Research in Marketing, 29(2), 192-201.

Guerreiro, R., Bio, S. R., \& Merschmann, E. V. V. (2008). Cost-to-serve measurement and customer profitability analysis. The international journal of logistics management, 19(3), 389-407.

Howcroft, J. (2005). Understanding profitability through cost-to-serve. Disponível em: www.advisorbase.co.nz/CosttoServe.pdf. Acesso em: 10 abr. 2018.

Kaplan, R. S.; Cooper, R. (1998). Custo e desempenho: administre seus custos para ser mais competitivo. São Paulo: Editora Futura.

Kone, E. R., \& Karwan, M. H. (2011). Combining a new data classification technique and regression analysis to predict the Cost-To-Serve new customers. Computers \& Industrial Engineering, 61(1), 184-197.

Martins, E. (2003). Contabilidade de custos. 9. ed. São Paulo: Atlas.

Martins, E. (2010). Contabilidade de custos. 10. ed. São Paulo: Atlas.

Mattos, M. A., Freitag, V. C., \& Starke Junior, P. C. S. (2010). Os Estágios Evolutivos da Contabilidade Gerencial: estudo aplicado às empresas prestadoras de serviços contábeis de Curitiba e região metropolitana. In Anais do Congresso Brasileiro de Custos- $A B C$, Curitiba.

Mauad, L. G. A., \& de Oliveira Pamplona, E. (2002). O Custeio ABC em empresas de serviços: características observadas na implantação em uma empresa do setor. In Anais do Congresso Brasileiro de Custos-ABC, Curitiba.

Nakagawa, M. (2001). ABC: Custeio Baseado em Atividades. São Paulo: Atlas. 
Norek, C. D., \& Pohlen, T. L. (2001). Cost knowledge: a foundation for improving supply chain relationships. The International Journal of Logistics Management, 12(1), 37-51.

Robles Jr, A., Robles, L. T., \& de Faria, A. C. (2005). Custos para servir: uma proposta de aplicação para uma empresa de tintas. Revista Universo Contábil, 1(1), 71-85.

Santos, W. J. L.; Padrones, K. G. S. A. (2015). Método de custeio baseado em atividades para educação básica: uma proposta de aplicação. Anais do XXVI Congresso Brasileiro de Custos, Curitiba.

Souza, A. A., Avelar, E. A., \& Boina, T. M. (2008). Gestão de custos e formação de preços em empresas de produção por encomenda: estudos de casos. Revista de Informação Contábil, 2(1), 56-81.

Souza, A. A., Noveli, M., Minello, Í. F., Endrici, J. O. M., \& Avelar, E. A. (2006). Análise de sistemas de informações utilizados como suporte para os processos de estimação de custos e formação de preços. ABCustos, 1(1).

Souza, F. F., Marçal, J. V. K., \& Gasparetto, V. (2019). Custos Para Servir E Rentabilidade De Clientes Em Uma Empresa De Desenvolvimento De Softwares. Sociedade, Contabilidade e Gestão, 14(2), 1-16.

SINDIVEST. Indústria têxtil e do vestuário em SC (2010). Disponível em:

http://www.sindivestcriciuma.com.br/index.php/o-setor. Acesso em: 05 mar. 2018.

Wernke, R. (2005). Análise de custo e preço de venda: ênfase em aplicações de casos nacionais. São Paulo: Saraiva. 